Proceedings of the National Conference on Neutron Scattering and the Complementary Methods in the Investigations of the Condensed Phases, Chlewiska 2007

\title{
Investigation of Structure and Conductivity of Superionic Conducting Materials Obtained on the Basis of Silver Iodide
}

\author{
Z. WiśnieWski ${ }^{a, b}$, L. GóRSKI ${ }^{a}$ AND D. ZASADA ${ }^{b}$ \\ ${ }^{a}$ Institute of Atomic Energy, Świerk, 05-400 Otwock, Poland \\ ${ }^{b}$ Military University of Technology, Gen. S. Kaliskiego 2, 00-908 Warsaw, Poland \\ Dedicated to Professor Jerzy Janik on the occasion of his 80th birthday \\ Conductivity and structure of materials belonging to pseudo-binominal \\ group $\left(\mathrm{AgI}-\mathrm{Ag}_{2} \mathrm{MoO}_{4}\right)$ were investigated. Structure was investigated by \\ $\mathrm{X}$-ray and scanning electron microscopy techniques. It was found that de- \\ scribed materials present a variety of internal structures. This type of struc- \\ tures affects conductivity at room temperature, so there is correspondence \\ between conductivity and structure.
}

PACS numbers: 61.05.C-, 61.43.Fs

\section{Introduction}

Superionic conductors constitute important and interesting but relatively weakly known group of materials. These materials exhibit electric conductivity comparable to those observed in semiconductors. Conductivity in these materials is however of completely different nature than in semiconductors because in semiconductors the conductivity is a result of movements of light electrons. In case of superionic conductors the conductivity is a result of movements of ions. Ions have considerable mass and volume. As a result in case of superionic conductors transport of electric charge is connected to transport of mass. It imposes special demands for conductivity measurements.

Because electric transport of superionic conductors occurs through ions with considerable volume, for such transport these materials must have special structure which means that in this structure in some directions interatomic distances must be big enough to enable ion movements [1-3]. These movements occur through 
so-called hopping mechanism. In order to understand in detail connection between structure and conductivity special structural investigation must be done. The best methods for analysis of structure of this material seems to be scanning electron microscopy (SEM), optical microscopy, X-ray scattering.

Applications of these methods are presented on the example of materials belonging to silver ion conductors described by formulae $x \mathrm{AgI}-(1-x)\left(\mathrm{Ag}_{2} \mathrm{O}-\mathrm{MoO}_{3}\right)$ [4]. Members of this group achieve one of the highest specific conductivity of all known superionic conductors. This group is also important from application point of view because the material found application in batteries for pacemakers.

Apart from this, superionic materials are presently finding wide application as super capacitors, solid state batteries, and highly selective chemical sensors.

\section{Experiment}

As a source materials $\mathrm{AgI}, \mathrm{Ag}_{2} \mathrm{O}$, and $\mathrm{MoO}_{3}$ (provided by Sigmaaldrich) were used. They were weighted, grinded in agate mortar, then they were placed in ceramic crucible and heated up to $800^{\circ} \mathrm{C}$ for $30 \mathrm{~min}$. Then they were rapidly quenched between two metal plates. Electrical measurements were done by impedance spectroscopy with impedance measured for frequency from $1 \mathrm{~Hz}$ to $10^{5} \mathrm{~Hz}$. For structural measurements optical microscopy, SEM, and X-ray scattering were applied. For X-ray scattering $\mathrm{Cu} K_{\alpha 1}$ radiation and diffractometer HZG-4 were used.

\section{Results and discussion}

\subsection{Electrical investigation}

For electricity measurements impedance spectroscopy was used. This method is suitable for measurements of ionic conductivity in solids because it gives better results than other measurements because it enables revealing complex nature of conductivity in superionic materials [5]. Additionally, the fact that electric charge transport is connected with mass transport makes application of usual direct current methods for conductivity measurements impossible, because it results in material decomposition. Impedance spectroscopy is a method where conductivity is measured by alternative current for broad range of frequencies. As a result of measurements for each frequency complex impedance is obtained with real and imaginary parts. These data can be analyzed in three ways. The first and the simplest way is finding frequency for which imaginary part is equal to 0 and its value could be named as sample resistance. The second method is plotting impedance vector modulus as a function of frequency. The third method of analysis is finding such replacing electric circuits which will produce the same impedance plot as investigated material.

In this investigation first approach was applied. As a resistivity value there was taken this value of $\operatorname{Re}(Z(\omega))$ for which $\operatorname{Im}(Z)$ is 0 or close to 0 . This method is independent of internal structure of the sample. 
It was found that in region where $x \leq 0.8$ resistivity of sample decreases with silver iodide concentration (Fig. 1A). In region where $x>0.8$ resistivity rapidly increases with silver iodide concentration (Fig. 1B).
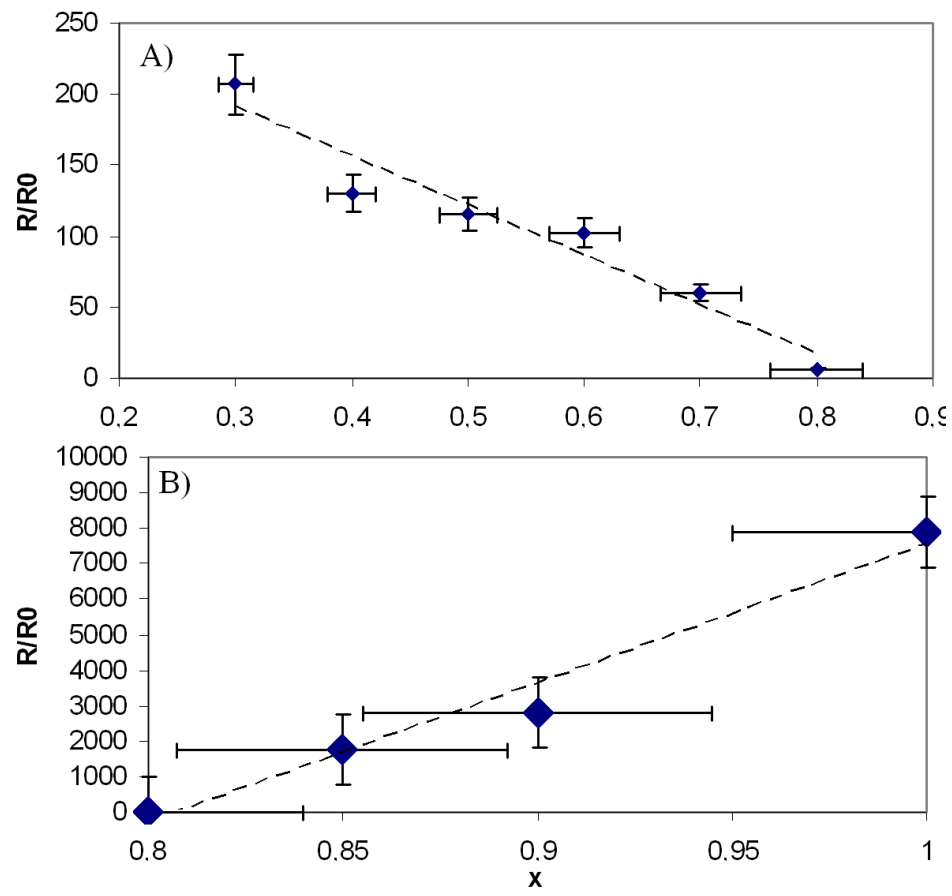

Fig. 1. Resistivity of $x \mathrm{AgI}-(1-x)\left(\mathrm{Ag}_{2} \mathrm{O}-\mathrm{MoO}_{3}\right)$ materials: A) for $x<0.8$, (B) for $x>0.8$.

These results could be better understood in view of results of structural investigation.

\subsection{Structural investigation}

Fractures of investigated samples were observed by SEM technique. Three different kinds of structures were observed.

For $x<0.5$ the structure showed great deal of regular crystallites which formed columnar structure (Fig. 2A).

As X-ray investigation showed (Fig. 3A), this structure was composed of glass matrix with $\mathrm{Ag}_{2} \mathrm{MoO}_{4}$ crystals. Another feature of this structure is the presence of large pores. In materials for which $0.5 \leq x \leq 0.8$ no X-ray peaks were observed (Fig. 3B) and structure observed by SEM microscope was homogeneous (Fig. 2A). Such homogeneous materials show the highest electrical conductivity. This high value of conductivity can be explained by the fact that concentration of silver iodide is high and conducting paths are not blocked. In such situation conductivity is proportional to number of mobile silver ions which is proportional 


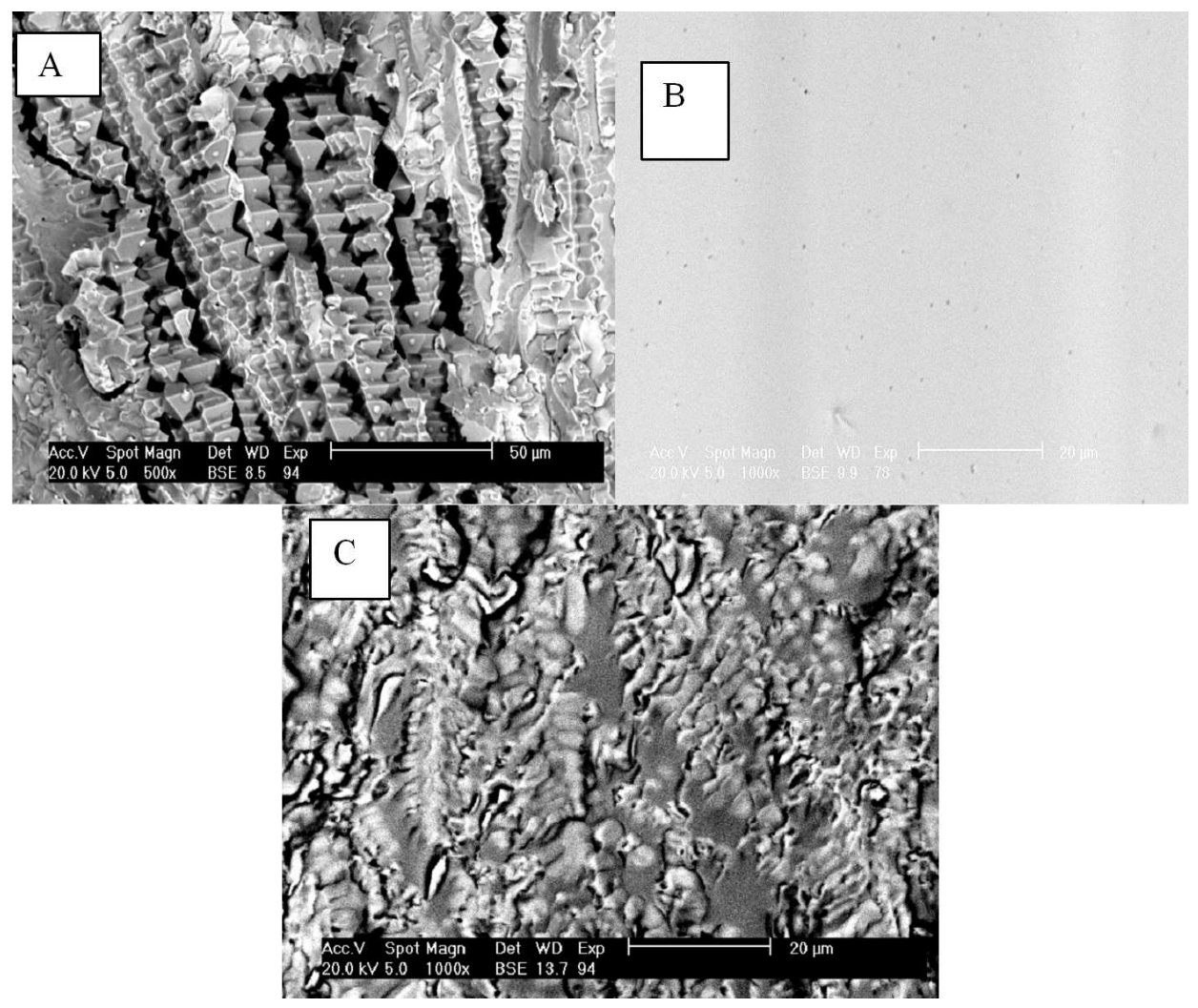

Fig. 2. SEM pictures of $x \mathrm{AgI}-(1-x)\left(\mathrm{Ag}_{2} \mathrm{O}-\mathrm{MoO}_{3}\right)$ materials: (A) $x=0.30$, (B) $x=$ 0.60, (C) $x=0.95$.

to amount of AgI. Further increase in amount of silver iodide in material does not lead however to increase in conductivity but to appearing of crystalline precipitates (Fig. 2C) which results in blocking conductivity channels. It was revealed by X-ray measurements that these precipitates have so-called $\beta$-AgI (Fig. 3C). This form is both ionic and electron insulating. So it is not surprising that for samples where $x>0.8$ the conductivity decreased with increase in AgI concentration.

Such behavior was similar to observed in case of $x \mathrm{AgI}-(1-x)\left(\mathrm{Ag}_{2} \mathrm{O}-\mathrm{P}_{2} \mathrm{O}_{5}\right)$ or $x \mathrm{AgI}-\left(\mathrm{Ag}_{2} \mathrm{O}-\mathrm{B}_{2} \mathrm{O}_{3}\right)[6,7]$, although in case of mentioned here materials for low concentration of AgI no crystalline precipitates were observed.

\section{Conclusions}

It was shown on example of $\mathrm{AgI}-\mathrm{Ag}_{2} \mathrm{O}-\mathrm{MoO}_{3}$ superionic conductors that for understanding electrical properties of superionic conductors not only electrical measurements, but also additional structural investigations are necessary.

For conductivity measurements the best method is impedance spectroscopy and for structural' measurements SEM, and X-ray investigations seem useful. Ap- 

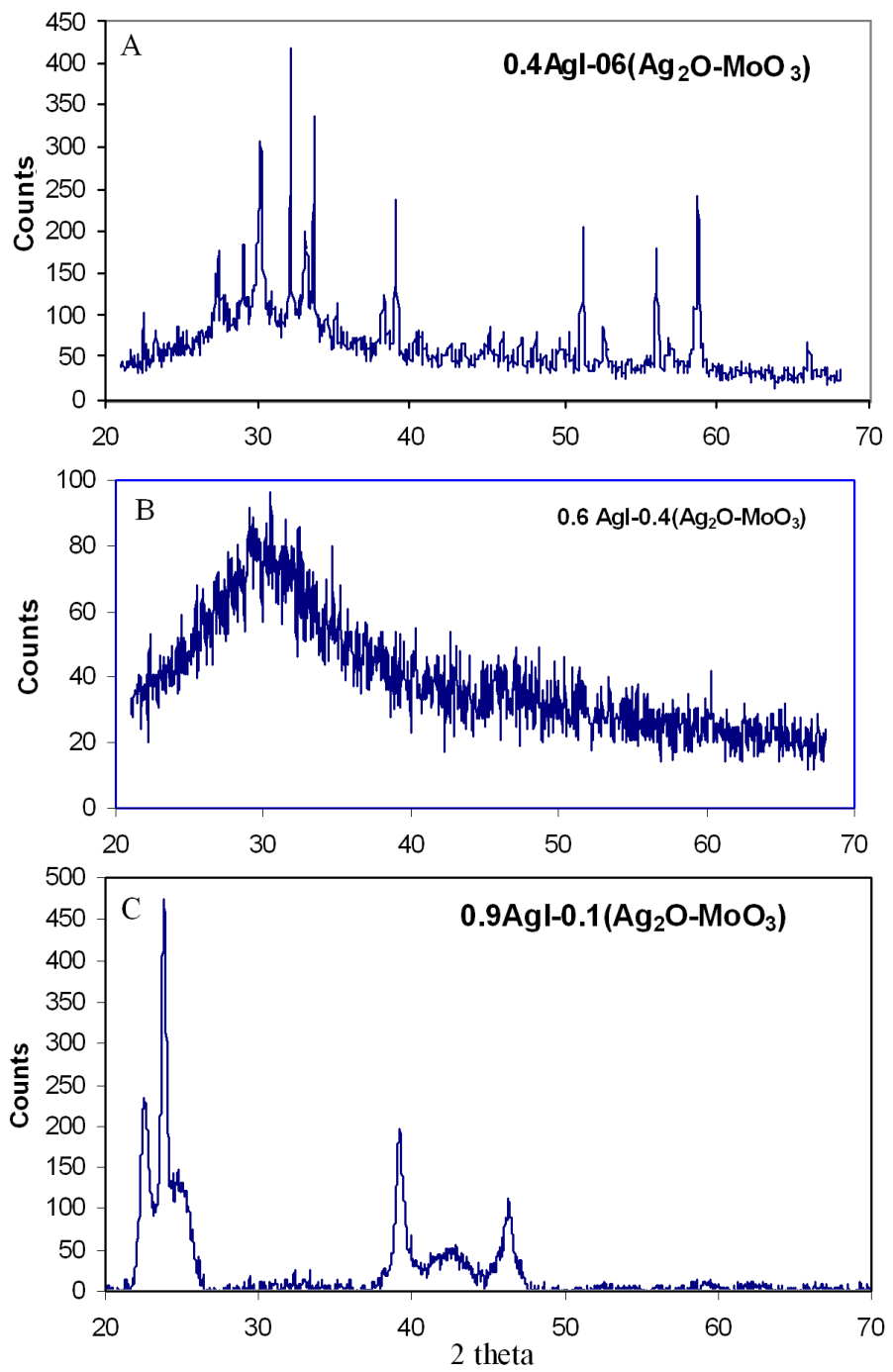

Fig. 3. X-ray patterns of $\mathrm{AgI}-\mathrm{Ag}_{2} \mathrm{O}-\mathrm{MoO}_{3}$ materials.

plication of these methods enabled to show that in $\mathrm{AgI}-\mathrm{Ag}_{2} \mathrm{O}-\mathrm{MoO}_{3}$ materials presence of crystalline precipitates and its chemical composition and phase determine their electrical conductivity leading usually to its decrease. This effect is stronger in case of $\mathrm{AgI}$ than in $\mathrm{Ag}_{2} \mathrm{MoO}_{4}$ precipitates.

\section{Acknowledgments}

The work was partially financed by resource for science for years 2006-2007 grant number 3 T08D 4530 . 


\section{References}

[1] A. Doi, J. Non-Crystalline Solids 246, 155 (1999).

[2] T. Takahashi; High Conductivity Solid Ionic Conductors: Recent Trends and Applications, World Sci., New Jersey 1989.

[3] M. Tatsumisago, M. Wakihara, C. Iwakura, S. Kohjiya, I. Tanaka, T. Minami, Solid State Ionics for Batteries, Springer, New York 2005.

[4] T. Minami, K. Imazawa, M. Tanaka, J. Non-Crystalline Solids 42, 469 (1980).

[5] E. Barsoukov, J. Ross Macdonald, Impedance Spectroscopy: Theory, Experiment and Applications, Wiley, Indianapolis 2005.

[6] J.L. Nowiński, J.E. Garbarczyk, M. Wasiucionek, B. Wnȩtrzewski, Mol. Phys. Rep. 35, 142 (2002).

[7] J.L. Nowiński, Mater. Sci. 24, 169 (2006). 